Research Article

\title{
Contemporary Results of Transcatheter Aortic Valve Replacement in Obese Patients
}

\author{
T. Owais $\mathbb{D}^{1,2}$ M. El Garhy $\mathbb{D}^{1,3,4}$ P. Lauten, ${ }^{1}$ M. Haensig $\mathbb{D},{ }^{1}$ H. Lapp, ${ }^{1}$ P. C. Schulze, ${ }^{4}$ \\ and T. Kuntze ${ }^{1}$ \\ ${ }^{1}$ Heart Centre, Zentralklinik Bad Berka, Bad Berka, Germany \\ ${ }^{2}$ Department of Cardiothoracic Surgery, Cairo University, Giza, Egypt \\ ${ }^{3}$ Department of Cardiology, Minia University, Minya, Egypt \\ ${ }^{4}$ Department of Internal Medicine I, Division of Cardiology, Pneumology, Angiology and Intensive Medical Care, \\ University Hospital Jena, Friedrich-Schiller-University Jena, Jena, Germany \\ Correspondence should be addressed to T. Owais; tamerowaiss1976@yahoo.com
}

Received 2 January 2020; Revised 9 May 2020; Accepted 26 May 2020; Published 15 June 2020

Academic Editor: Simon W. Rabkin

Copyright (C) 2020 T. Owais et al. This is an open access article distributed under the Creative Commons Attribution License, which permits unrestricted use, distribution, and reproduction in any medium, provided the original work is properly cited.

\begin{abstract}
Background. Little research has been conducted to explore the postoperative outcomes of obese patients after transfemoral transcatheter aortic valve replacement (TF-TAVR). Objective. We investigated the influence of body mass index (BMI) on 1-year outcomes after TF-TAVR. Methods. We included retrospectively 1609 high- and intermediate-risk TAVR patients (mean EuroSCORE II $21 \pm 11$ ) operated under general anesthesia between March 2014 and March 2018 in central hospital, Bad Berka, Germany. We stratified the patients according to BMI. Results. Our demographic data analysis showed $41 \%$ of patients were male and the mean age was 78 (range, 61-92 years). According to the WHO classification, 33\% patients had normal weight, $42 \%$ were defined as overweight, and $22 \%$ were obese. Obese patients showed statistically significant difference in their clinical parameters as having higher incidence of hypertension, diabetes mellitus, pulmonary hypertension, and chronic obstructive pulmonary disease; on the contrary, obese patients were found to be younger than others. We found no differences in valve types and sizes among the different BMI categories. Our mortality rate during the 1-year follow-up period was $17.8 \%$ (287 patients). Mortality was significantly higher in patients with $\mathrm{BMI}<25 \mathrm{~kg} / \mathrm{m}^{2}$ (1 year mortality 149 patients $28.2 \%$ in patients with $\mathrm{BMI}<25 \mathrm{~kg} / \mathrm{m}^{2} \mathrm{vs} .138$ patients $12.6 \%$ in patients with $\mathrm{BMI} \geq 25 \mathrm{~kg} / \mathrm{m}^{2} ; P=0.0001$ ). Even after considering the confounding risk factors, BMI $\geq 25 \mathrm{~kg} / \mathrm{m}^{2}$ was independently associated with reduced 1 year mortality (odds ratio (OR): $0.36,95 \%$ confidence interval (CI): $0.21-0.6$; $P=0.01)$ in multivariate logistic regression analysis. The rate of vascular complication was higher in patients with $\mathrm{BMI} \geq 25 \mathrm{~kg} /$ $\mathrm{m}^{2}$. However, the rate of blood transfusion was higher in patients with $\mathrm{BMI}<25 \mathrm{~kg} / \mathrm{m}^{2}$. All other serious complications occurred with equal distribution in both groups. Conclusion. In our single-center study, BMI $\geq 25 \mathrm{~kg} / \mathrm{m}^{2}$ was independently associated with lower 1 year mortality after TF-TAVR.
\end{abstract}

\section{Introduction}

Obesity is considered to be a morbidity- and mortalitydependent cardiovascular factor [1]. However, this clinical factor is still under investigation in the literature in the domain of transcatheter aortic valve replacement (TAVR). Nevertheless, several studies expressed obese patients as having better outcomes when compared with nonobese patients in aortic valve replacement procedures $[2,3]$ and in percutaneous coronary intervention [4]. Tokarek et al. showed that increased BMI was independently associated with 1-year survival benefit after TAVR. However, there was no difference between the groups in terms of 30-day allcause mortality [5].

As for the progressively increasing population and awareness to medical consequences, it would be logical to expect greater number of obese patients with aortic valve stenosis referred for TAVR. In this study, we evaluated how influential is the body mass index (BMI) on TAVR outcomes concerning procedure-related complications and mortality. 


\subsection{Study Population and Data Collection}

\subsubsection{Methods}

(1) Study Design and Follow-Up. In this study, we retrospectively collected data of TAVR patients in our institute (Zentralklinik Bad Berka, Germany) in the period between March 2014 and March 2018. All patients signed routinely an informed consent preoperatively. Clinical, echocardiographic, and hemodynamic criteria were our diagnostic tools. Computerised tomography was our preparatory tool. Eligibility for TAVR was determined by our heart team. We collected 1609 patients in this period who underwent transfemoral TAVR. After hospital discharge, all patients were subjected to follow-up schedule at 3 months and 1 year. Mortality data were collected by contacting the patients and the referring physicians.

(2) TAVR Procedure. TAVR was performed under general anesthesia. Three types of aortic valve prostheses were used: the Evolut aortic valve prosthesis (Medtronic, Inc., Minneapolis, $\mathrm{MN})(23,26,29$, or $34 \mathrm{~mm})$, the Edwards SAPIEN 3 prosthesis (Edwards Lifesciences Corp, Irvine, CA) $(23,26$, and $29 \mathrm{~mm}$ ), and the Symetis aortic valve prosthesis (Boston Scientific) (small, medium, and large). Two senior TAVR operators (a cardiac surgeon and an interventional cardiologist) were in charge of the whole procedure. Valve type and size were decided preoperatively according to CT and echocardiography. All intraoperative and postoperative special findings or complications were always recorded and documented.

(3) End Points. Periprocedural complications and mortality rates were evaluated according to VARC-2 definitions [6]. End points of the study were all-cause mortality at 1 year, major and life-threatening bleeding complications, major vascular complications, blood transfusions, cerebrovascular events, and need for permanent pacemakers following the procedure.

(4) BMI (Body Mass Index). This parameter was obtained from patients' files by dividing the weight in kilograms by the square of the height in meters. We classified the patients into three groups: normal weight, BMI from 18.5 to $24.9 \mathrm{~kg} /$ $\mathrm{m}^{2}$; overweight, BMI from 25.0 to $29.9 \mathrm{~kg} / \mathrm{m}^{2}$; and obese, $\mathrm{BMI} \geq 30 \mathrm{~kg} / \mathrm{m}^{2}$. In our cohort, only $1 \%$ of the patients were classified as underweight and being statistically noninfluential. This group was excluded from our study.

Before 01/2018, all TAVR patients were treated postoperatively with dual antiplatelet therapy (aspirin and clopidogrel) for 6 weeks and then monotherapy lifelong. Since $01 / 2018$, all TAVI patients were treated postoperatively with monotherapy either aspirin or clopidogrel in the absence of indication to anticoagulation or anticoagulants.

(5) Statistical Analysis. All data were displayed as mean (standard deviation) for continuous variables and as the number (percentage) of patients in each group for categorical variables. Student's $t$-test or the analysis of variance test was used to evaluate the statistical significance between continuous variables, whereas the $\chi^{2}$ test was used in case of categorical variables, respectively. Odds ratios were calculated with a confidence interval of 95\%. The analysis was done for BMI as continuous as well as categorical variables $\left(\mathrm{BMI}<\right.$ or $\left.25 \mathrm{~kg} / \mathrm{m}^{2}\right)$. Furthermore, multivariate analysis is performed to explore the association between BMI $\geq 25 \mathrm{~kg} /$ $\mathrm{m}^{2}$ and 1 year mortality. All of the analyses were considered significant at a 2 -tailed $P$ value of $<0.05$. All analyses were done using SPSS statistical software (IBM Corp. released 2013, IBM SPSS Statistics for Windows, version 22.0, Armonk, NY).

\section{Results}

Our total study cohort included 1609 patients (41\% males) with a mean age of 78 (range, 61-92 years). Our demographic data analysis showed that the mean logistic EuroSCORE of the study patients was $21 \%, 88 \%$ of patients suffering from hypertension, 19\% from COPD, $12 \%$ from $\mathrm{PH}, 57 \%$ from carotid stenosis, and 34\% from diabetes. $28 \%$ of patients were classified as New York Heart Association class IV. Edwards SAPIEN 3 was implanted in $60 \%$ of patients, while the Evolut prosthesis was used in $31 \%$ of patients and Symetis prosthesis in $9 \%$ of patients. The clinical characteristics of patients according to their BMI classification are presented in Table 1. According to the WHO classification, $1 \%$ of patients were defined as underweight, $33 \%$ had normal weight, $42 \%$ were defined as overweight, and $22 \%$ were obese. As shown in Table 1, the obese patients showed statistically significant difference in their clinical parameters as having higher incidence of hypertension, diabetes mellitus, pulmonary hypertension, and chronic obstructive pulmonary disease; on the contrary, obese patients were found to be younger than others and consequently have lower logistic EuroSCORE. We found no differences in valve types and sizes among the different BMI categories.

Our mortality rate during the 1-year follow-up period was $17.8 \%$ (287 patients). Mortality was significantly higher in patients with $\mathrm{BMI}<25 \mathrm{~kg} / \mathrm{m}^{2}$ (The 1 -year mortality in patients with $\mathrm{BMI}<25 \mathrm{~kg} / \mathrm{m}^{2}$ was $28.2 \%$ (149 patients) vs $12.6 \%$ (138 patients) in patients with $\mathrm{BMI} \geq 25 \mathrm{~kg} / \mathrm{m}^{2}$; $P=0.0001$ ), see Figure 1. Even after considering the confounding risk factors, $\mathrm{BMI} \geq 25 \mathrm{~kg} / \mathrm{m}^{2}$ was independently associated with reduced 1 year mortality (odds ratio (OR): $0.36,95 \%$ confidence interval $(\mathrm{CI}): 0.21-0.6 ; P=0.01)$ in multivariate logistic regression analysis, as shown in Table 2 und Figure 2. The rate of vascular complication was lower in patients with $\mathrm{BMI} \geq 25 \mathrm{~kg} / \mathrm{m}^{2}$. However, the rate of blood transfusion was higher in patients with $\mathrm{BMI}<25 \mathrm{~kg} / \mathrm{m}^{2}$. All other serious complications occurred with equal distribution in both groups, as shown in Table 3 .

\section{Discussion}

In this retrospective observational study, we targeted to focus on the influence of BMI on TAVR outcomes. The principle conclusion was patients with $\mathrm{BMI} \geq 25 \mathrm{~kg} / \mathrm{m}^{2}$ had lower long-term mortality rates and, on the other hand, higher rate of procedure-related complications. As reported 
TABLe 1: Baseline clinical characteristics of patients according to BMI classification.

\begin{tabular}{|c|c|c|c|c|c|}
\hline Variables & $\begin{array}{l}\text { Entire cohort, } \\
1609 \text { patients }\end{array}$ & $\begin{array}{c}18.5<\text { BMI } \leq 24.9, \text { normal } \\
\text { weight, } 528 \text { patients }\end{array}$ & $\begin{array}{c}25 \leq \text { BMI } \leq 29.9, \text { overweight } \\
676 \text { patients }\end{array}$ & $\begin{array}{l}\mathrm{BMI} \geq 30, \text { obese } \\
405 \text { patients }\end{array}$ & $\begin{array}{c}P \\
\text { value }\end{array}$ \\
\hline Age (years), mean $\pm S D$ & $78 \pm 6.2$ & $86 \pm 6$ & $81 \pm 5$ & $78 \pm 6$ & 0.01 \\
\hline Gender (male), $n$ (\%) & $692(41)$ & $216(41)$ & $332(50)$ & $124(30)$ & 0.01 \\
\hline Diabetes mellitus, $n(\%)$ & $562(34)$ & $136(26)$ & $232(34)$ & $188(46)$ & 0.005 \\
\hline Hypertension, $n(\%)$ & $1436(88)$ & $436(81)$ & $608(90)$ & $380(93)$ & 0.012 \\
\hline Dyslipidemia, $n(\%)$ & $1280(77)$ & $400(75)$ & $528(78)$ & $336(82)$ & 0.41 \\
\hline Smoking, ever, $n(\%)$ & $421(27)$ & $128(24)$ & $160(24)$ & $124(30)$ & 0.42 \\
\hline PVD, $n(\%)$ & $152(6)$ & $56(12)$ & $44(6)$ & $16(4)$ & 0.137 \\
\hline $\mathrm{CAD}, n(\%)$ & $951(57)$ & $316(59)$ & $408(60)$ & $236(56)$ & 0.73 \\
\hline $\begin{array}{l}\mathrm{GFR}(\mathrm{MDRD}) \\
\left(\mathrm{mL} / \mathrm{min} / 1.73 \mathrm{~m}^{2}\right) \\
\text { mean } \pm \mathrm{SD}\end{array}$ & $58 \pm 15$ & $62 \pm 19$ & $65 \pm 20$ & $56 \pm 17$ & $<0.01$ \\
\hline Albumin $(\mathrm{g} / \mathrm{l})$ & $42 \pm 2.8$ & $42 \pm 3.7$ & $42 \pm 2.6$ & $43 \pm 3.5$ & 0.09 \\
\hline Atrial fibrillation, $n(\%)$ & $484(31)$ & $184(35)$ & $168(25)$ & $128(30)$ & 0.17 \\
\hline Prior stroke, $n(\%)$ & $159(9)$ & $52(10)$ & $64(10)$ & $40(10)$ & 0.99 \\
\hline COPD, $n(\%)$ & $316(19)$ & $84(16)$ & $112(17)$ & $120(29)$ & 0.015 \\
\hline Previous PCI, $n(\%)$ & $704(42)$ & $236(45)$ & $300(45)$ & $164(41)$ & 0.65 \\
\hline Previous MI, $n(\%)$ & $272(16)$ & $116(22)$ & $92(14)$ & $60(15)$ & 0.12 \\
\hline CABG, $n(\%)$ & $251(16)$ & $92(17)$ & $144(21)$ & $44(11)$ & 0.08 \\
\hline \multicolumn{6}{|l|}{ NYHA class, $n(\%)$} \\
\hline III & $1084(68)$ & $288(54.5)$ & $520(48)$ & $264(65)$ & \\
\hline IV & $471(28)$ & $220(42)$ & $116(17)$ & $124(31)$ & $<0.01$ \\
\hline Barthel index $<80$ & $209(13 \%)$ & $61(11.5 \%)$ & $86(12.7 \%)$ & $62(15.3 \%)$ & 0.08 \\
\hline EuroSCORE, mean \pm SD & $21 \pm 17$ & $24 \pm 12$ & $24 \pm 11$ & $21 \pm 9$ & 0.01 \\
\hline $\begin{array}{l}\text { Aortic valve area }\left(\mathrm{cm}^{2}\right) \\
\text { mean } \pm S D\end{array}$ & $0.6 \pm 0.3$ & $0.6 \pm 0.2$ & $0.6 \pm 0.1$ & $0.7 \pm 0.2$ & 0.073 \\
\hline $\begin{array}{l}\text { Ejection fraction (\%), } \\
\text { mean } \pm \text { SD }\end{array}$ & $59 \pm 6.9$ & $56.1 \pm 8.9$ & $52.8 \pm 6.1$ & $61.4 \pm 7.5$ & 0.058 \\
\hline $\begin{array}{l}\text { Valve type (Evolut), } n \\
(\%)\end{array}$ & $499(31)$ & $221(41)$ & $161(23)$ & $117(28)$ & 0.08 \\
\hline
\end{tabular}

BMI, body mass index; CABG, coronary artery bypass graft; CAD, coronary artery disease; COPD, chronic obstructive pulmonary disease; GFR (MDRD), glomerular filtration rate (modification of diet in renal disease); MI, myocardial infarction; NYHA, New York Heart Association; PCI, percutaneous coronary intervention; PVD, peripheral vascular disease; SD, standard deviation.

by the Nutrition Council of the American Heart Association, obesity is considered a risk factor for cardiovascular morbidity and mortality [1]. Obesity rates are progressively rising due to the sedentary life style and still associated with higher morbidity and mortality $[7,8]$. On the contrary, Batty et al. and Lancefield et al. reported a better survival rates among obese patients $[9,10]$.

TAVR is known to be indicated in high and intermediate surgical risk candidates for aortic valve replacement [11]. However, to our knowledge, the BMI is an absent parameter in logistic EuroSCORE, and consequently, its influence on the TAVR outcomes has not been directly investigated in detail. Van der Boon et al. showed that obesity was associated with a decrease in 30-day mortality, but had no effect on long-term outcomes [12]. This conclusion point differs from our results in the following aspects: our cohort group is bigger in comparison with his as they retrospectively investigated 944 patients vs 1609 patients in our study. However, on the contrary, they reported no increase in procedure-related complications among the obese group which is opposite to what we found out in our study. Despite an increase in our periprocedural complications, we found lower 1-year mortality in patients with $\mathrm{BMI} \geq 25 \mathrm{~kg} / \mathrm{m}^{2}$. We would explain this finding by the fact that overweight patients might have more metabolic reserves [13]. Another explanation might be the fact that we were introducing a new closure device in our institute during the phase where this study was conducted. Our results go on line with the recent analysis from the FRANCE2 (French Aortic National CoreValve and Edwards 2) registry, according to which, among the TAVR population, overweight and obesity were associated with improved 1-year survival [14]. BMI remained an independent predictor of improved survival in multivariate analysis. This might be explained by the fact that overweight and obese patients are usually intensively treated with optimum medical therapy for the associated risk factors and consequently contributing to better outcomes [13].

Blood transfusion was found to be less frequent in the obese cohort in our study group. Despite the fact that hemoglobin level was similar among all groups on admission and the increased number of procedure-related complications in the obese group, we would interpret this as those patients were seen as less frail and less fragile and hence blood transfusion in this group was restricted only to patients suffering from progressive anemia and active bleeding; therefore, overall, patients defined as obese were treated with blood transfusion less frequently. Several studies support our results [15-17]. 


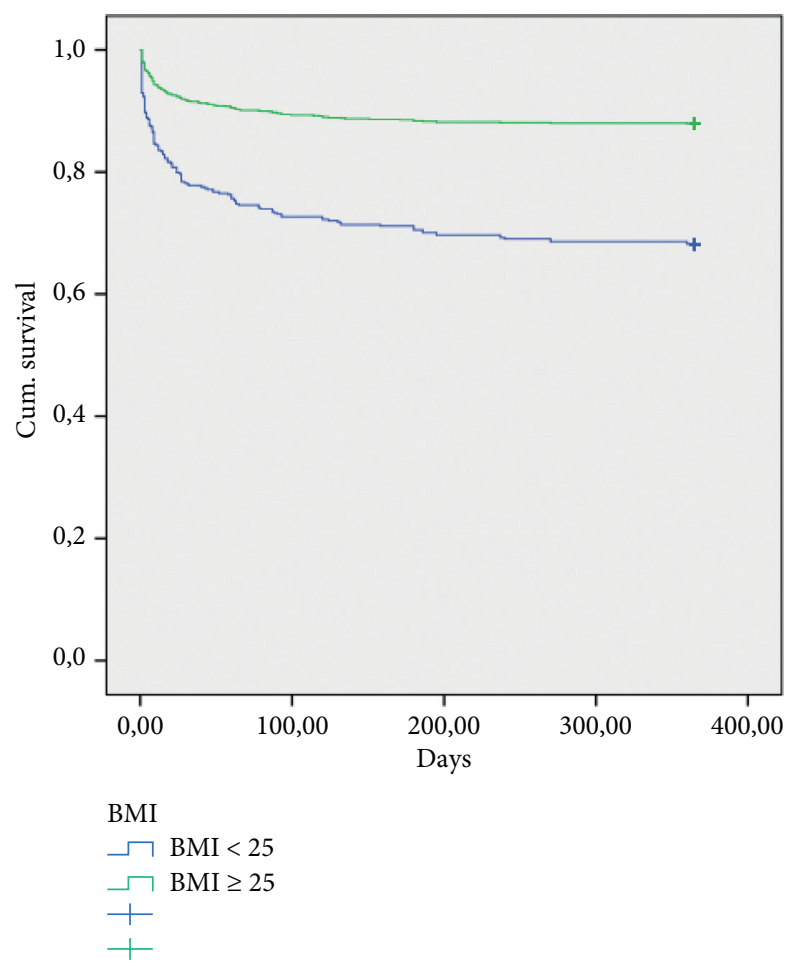

FIGURE 1: Kaplan-Meier curve showing the survival curve of patients with $\mathrm{BMI}<25$ compared with patients with $\mathrm{BMI} \geq 25$.

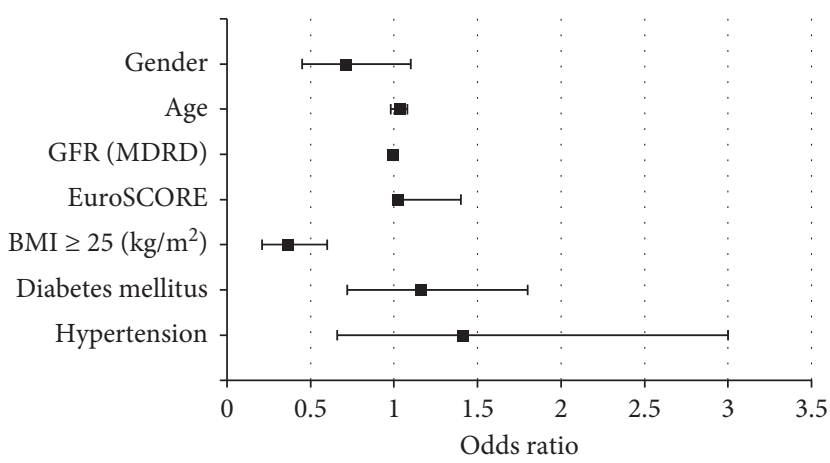

FIgURE 2: Odds ratio for 1-year mortality in study patients.

TABLe 2: Multivariate Cox proportional hazard model.

\begin{tabular}{lccc}
\hline Variables & Hazard ratio & Confidence interval & $P$ value \\
\hline Gender & 0.71 & $0.45-1.14$ & 0.16 \\
Age & 1.03 & $0.98-1.08$ & 0.15 \\
Diabetes mellitus & 1.16 & $0.72-1.87$ & 0.53 \\
Hypertension & 1.41 & $0.66-3.00$ & 0.36 \\
COPD & 1.63 & $0.96-2.78$ & 0.07 \\
GFR (MDRD) & 0.99 & $0.97-1.00$ & 0.13 \\
EuroSCORE & 1.02 & $1.01-1.4$ & $<0.001$ \\
BMI $\geq 25 \mathrm{~kg} / \mathrm{m}^{2}$ & 0.36 & $0.21-0.6$ & 0.01 \\
\hline
\end{tabular}

BMI, body mass index; COPD, chronic obstructive pulmonary disease; GFR (MDRD), glomerular filtration rate (modification of diet in renal disease); NYHA, New York Heart Association.

3.1. Study Limitations. The main limitation of this study is being a retrospective observational study and there may have residual confounders (as the indicators of central obesity, CT measurements of visceral fat, and medications) that we did not account for. Another limitation of the current study is that the clinical follow-up for more than one year was not available, which might decrease the influence of important predictors such as age on mortality. 
TABle 3: Clinical outcomes according to BMI classification.

\begin{tabular}{|c|c|c|c|c|c|}
\hline & $\begin{array}{l}\text { Entire cohort, } \\
1609 \text { patients }\end{array}$ & $\begin{array}{l}\text { BMI } \leq 24.9 \text {, normal } \\
\text { weight, } 528 \text { patients }\end{array}$ & $\begin{array}{c}25 \leq \mathrm{BMI} \leq 29.9, \text { overweight } \\
676 \text { patients }\end{array}$ & $\begin{array}{c}\mathrm{BMI} \geq 30, \text { obese } \\
405 \text { patients }\end{array}$ & $\begin{array}{c}P \\
\text { value }\end{array}$ \\
\hline $\begin{array}{l}\text { Vascular complications, } \\
n(\%)\end{array}$ & $140(9)$ & $36(5)$ & $40(7)$ & $64(18)$ & 0.015 \\
\hline $\begin{array}{l}\text { Major/life-threatening } \\
\text { bleeding, } n(\%)\end{array}$ & $212(15)$ & $48(11)$ & $84(13)$ & $80(22)$ & 0.055 \\
\hline Blood transfusions, $n(\%)$ & $532(38)$ & $220(49)$ & $192(31)$ & $120(35)$ & 0.01 \\
\hline $\begin{array}{l}\text { New atrial fibrillation, } n \\
(\%)\end{array}$ & $112(7)$ & $40(7.5)$ & $40(6)$ & $32(8)$ & 0.78 \\
\hline New pacemaker, $n(\%)$ & $344(21)$ & $96(17.5)$ & $128(18)$ & $120(30)$ & 0.067 \\
\hline Acute kidney injury, $n(\%)$ & $196(12)$ & $64(12)$ & $80(12)$ & $52(13)$ & 0.96 \\
\hline $\begin{array}{l}\text { Cerebral ischemic event, } \\
n(\%)\end{array}$ & $88(5.4)$ & $24(4)$ & $44(6)$ & $20(5)$ & 0.71 \\
\hline
\end{tabular}

BMI, body mass index.

\section{Conclusion}

In our single-center study, BMI $\geq 25 \mathrm{~kg} / \mathrm{m}^{2}$ was independently associated with lower 1-year mortality after transfemoral TAVR.

\section{Data Availability}

The data used to support the findings of this study have not been made available because of the absence of hospital agreement.

\section{Conflicts of Interest}

The authors declare that they have no conflicts of interest.

\section{Authors' Contributions}

Owais T and El Garhy M contributed equally to this work.

\section{References}

[1] P. Poirier, T. D. Giles, G. A. Bray et al., "Obesity and cardiovascular disease: pathophysiology, evaluation, and effect of weight loss," Circulation, vol. 113, no. 6, pp. 898-918, 2006.

[2] M. Vaduganathan, R. Lee, and A. J. Beckham, "Relation of body mass index to late survival after valvular heart surgery," The American Journal of Cardiology, vol. 110, no. 11, pp. 1667-1678, 2012.

[3] V. H. Thourani, G. Ailawadi, W. Y. Szeto et al., "Outcomes of surgical aortic valve replacement in high-risk patients: a multiinstitutional study," The Annals of Thoracic Surgery, vol. 91, no. 1, pp. 49-56, 2011.

[4] L. Gruberg, N. J. Weissman, R. Waksman et al., "The impact of obesity on the short-term andlong-term outcomes after percutaneous coronary intervention: the obesity paradox?" Journal of the American College of Cardiology, vol. 39, no. 4, pp. 578-584, 2002.

[5] T. A. Tokarek, A. Dziewierz, D Sorysz et al., "The obesity paradox in patients undergoing transcatheter aortic valve implantation: is there any effect of body mass index on survival?" Kardiologia Polska, vol. 77, pp. 190-197, 2018.

[6] A. P. Kappetein, S. J. Head, P Généreux et al., "Updated standardized endpoint definitions for transcatheter aortic valve implantation: the valve academic research consortium- 2 consensus document," The Journal of Thoracic and Cardiovascular Surgery, vol. 145, no. 1, pp. 6-23, 2013.

[7] Expert Panel on the Identification, Evaluation, and Treatment of Overweight and Obesity in Adults, "Executive summary of the clinical guidelines on the identification, evaluation, and treatment of overweight and obesity in adults," Archives of Internal Medicine, vol. 158, no. 17, pp. 1855-1867, 1998.

[8] K. F. Adams, A. Schatzkin, T. B. Harris et al., "Overweight, obesity, and mortality in a large prospective cohort of persons 50 to 71 years old," New England Journal of Medicine, vol. 355, no. 8, pp. 763-778, 2006.

[9] G. D. Batty, M. J. Shipley, and R. J. Jarrett, "Obesity and overweight in relation to disease-specific mortality in men with and without existing coronary heart disease in London: the original Whitehall study," Heart, vol. 92, no. 7, pp. 886892, 2006.

[10] T. Lancefield, D. J. Clark, N. Andrianopoulos et al., "Is there an obesity paradox after percutaneous coronary intervention in the contemporary era?" JACC: Cardiovascular Interventions, vol. 3, no. 6, pp. 660-668, 2010.

[11] M. B. Leon, C. R. Smith, M. J. Mack et al., "Transcatheter or surgical aortic-valve replacement in intermediate-risk patients," New England Journal of Medicine, vol. 374, no. 17, pp. 1609-1620, 2016.

[12] R. M. A. van der Boon, A. Chieffo, N. Dumonteil et al., "Effect of body mass index on short- and long-term outcomes after transcatheter aortic valve implantation," The American Journal of Cardiology, vol. 111, no. 2, pp. 231-236, 2013.

[13] M. Konigstein, O. Havakuk, Y. Arbel et al., “The obesity paradox in patients undergoing transcatheter aortic valve implantation," Clinical Cardiology, vol. 38, no. 2, pp. 76-81, 2015.

[14] M. Yamamoto, G. Mouillet, A. Oguri et al., "Effect of body mass index on 30-and 365-day complication and survival rates of transcatheter aortic valve implantation (from the French Aortic National CoreValve and Edwards 2 [France 2] registry)," The American Journal of Cardiology, vol. 112, no. 12, pp. 1932-1937, 2013.

[15] R.-J. Nuis, J. Rodés-Cabau, J.-M. Sinning et al., "Blood transfusion and the risk of acute kidney injury after transcatheter aortic valve implantation," Circulation: Cardiovascular Interventions, vol. 5, no. 5, pp. 680-688, 2012.

[16] R.-J. M. Nuis, N. M. Van Mieghem, A. Tzikas et al., "Frequency, determinants, and prognostic effects of acute kidney injury and red blood cell transfusion in patients undergoing 
transcatheter aortic valve implantation," Catheterization and Cardiovascular Interventions, vol. 77, no. 6, pp. 881-889, 2011.

[17] D. Tchetche, R. M. A. Van der Boon, N. Dumonteil et al., "Adverse impact of bleeding and transfusion on the outcome post-transcatheter aortic valve implantation: insights from the Pooled-RotterdAm-Milano-Toulouse in collaboration plus (PRAGMATIC Plus) initiative," American Heart Journal, vol. 164, no. 3, pp. 402-409, 2012. 